ENTREPRENEURSHIP AND SUSTAINABILITY ISSUES

ISSN 2345-0282 (online) http://jssidoi.org/jesi/

2020 Volume 7 Number 4 (June)

http://doi.org/10.9770/jesi.2020.7.4(37)

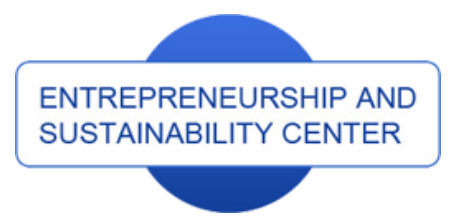

Publisher

http://jssidoi.org/esc/home

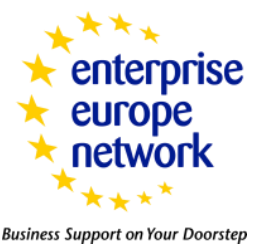

Business Support on Your Doorstep

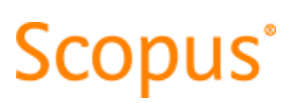

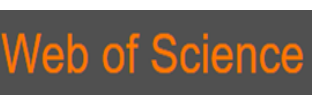

1) Clarivate

Analytics

\title{
METHOD FOR EVALUATING THE POSSIBILITY OF CLUSTER FORMING
}

\author{
Arkadii A. Simdiankin ${ }^{1}$, Pavel S. Probin ${ }^{* 2}$, Larisa N. Gerasimova ${ }^{3}$, Zhanna A. Kevorkova ${ }^{4}$, \\ Vadim A. Dikikh ${ }^{5}$, Aslan O. Nurmanov 6 \\ ${ }^{1,2}$ Russian State University of Physical Education, Sport, Youth and Tourism (SCOLIPE), Sireneviy boulevard, 4, \\ Moscow, 105122, Russian Federation. \\ ${ }^{3}$ Moscow State University of Civil Engineering (National Research University) (MGSU), Yaroslavskoe shosse, 26, Moscow, \\ 129337, Russian Federation \\ ${ }^{4}$ Financial University under the Government of the Russian Federation, Leningradsky Prospekt 49, Moscow, 125993 Russian \\ Federation \\ ${ }^{5}$ Moscow City Teacher Training University, 2nd Agricaltural fare, 4, Moscow, Russian Federation \\ ${ }^{6}$ Aktobe regional state University named after K. Zhubanov, A. Moldagulova street 34, Aktobe, 030000, Kazakhstan republic \\ E-mail: *22probinpavel@mail.ru (Corresponding author)
}

Received 15 November 2019; accepted 22 April 2020; published 30 June 2020

\begin{abstract}
Over the past few years clustering has undergone significant changes as a tool for economic development. Now it is actively positioned as an intensifier of the transition of the current economic model to the digital channel. At the same time issues of ensuring high socio-economic efficiency of individual cluster initiatives are relevant both for Russia and for countries with developed market economies. This is largely due to the emerging crisis in the modern theory and methodology of the cluster approach. The authors consider some existing approaches of clusterization and assessment methods to indicate the disadvantages that do not allow to justify the need to establish an effectively functioning cluster. The method of geometric drawing of cluster objects based on ranking of services provided by its members with subsequent interpretation of the positions of the actual and geometric centers of the cluster is proposed.
\end{abstract}

Keywords: cluster; clustering center; cluster core; geographical border; main and secondary organizations; ranking; significance; sports and dance cluster; "temporary" cluster; thematic border

Reference to this paper should be made as follows: Simdiankin, A.A., Probin, P.S., Gerasimova, L.N., Kevorkova, Zh. A., Dikikh, V.A., Nurmanov, A.O. 2020. Method for evaluating the possibility of cluster forming. Entrepreneurship and Sustainability Issues, 7(4), 31453157. https://doi.org/10.9770/jesi.2020.7.4(37)

Jel codes: M21, M40, G32

Additional disciplines: Financial economics 


\section{ENTREPRENEURSHIP AND SUSTAINABILITY ISSUES}

ISSN 2345-0282 (online) http://jssidoi.org/jesi/

2020 Volume 7 Number 4 (June)

http://doi.org/10.9770/jesi.2020.7.4(37)

\section{Introduction}

Clustering is considered to be one of the most effective and universal drivers of development in the context of economic instability (Abdurakhmanov, 2018). This circumstance is primarily due to the synergy effect achieved through the interaction of business structures, the state, research centers and universities, which forms the basis for a system of financial and non-financial incentives to support business (Egorova, 2014). At the same time the interests of all cluster participants are balanced as well as the basis for healthy competition and the development of market relations is created (Nikulina \& Yakunina, 2011). The special role of clusters in European countries is to develop the Institute of small and medium-sized businesses, in particular in the context of the development of a "cyclical" economics (Nielsen, 2019; Petrenko et al., 2019). Some authors compare performace of clusters in different countries (El Idrissi et al., 2020).

Some authors (Charykova \& Markova, 2019) emphasize the importance of the cluster approach in the context of the transition of the historically established economic model to the digital channel. Other scientists (Kiseleva \& Samodinsky, 2018) also note the role of public-private collaboration tools in the development of the digital economy where clustering is the most important part. Some experts (Turgel, Bozhko \& Zinovieva, 2019) justify the crucial importance of the cluster approach in the development of free economic zones, in particular from the point of view of international partnership.

We will not consider in detail the evolution of the cluster approach (Bondarenko, 2016) but we will analyze the most significant problems in this area at the present stage.

\section{Literature review}

There are a lot of publications that focused on clarifying the concept of "cluster". For example, some authors (Kolesnikov \& Khazalia, 2016) studied the evolution of the concept of "cluster" for the period from 1992 to 2008. They identify cluster as "a set of organizations and institutions interacting in a particular sphere of activity where competition and cooperation (coordinated actions) lead to a competitiveness increase of each of them due to such factors as aggregate efficiency (exchange of knowledge and information, network effects, savings from diversity), training, and economies of scale".

In the press release "Clusters in the circular economy. Building Partnerships for Sustainable Transition of SMEs" the authors specify: today many clusters are defined by a group of companies when the most important element of such a partnership is cooperation with research organizations, the state, private investors and startups in order to make effectively interaction in defined technological areas. It describes cluster as a neutral platform that is independent of political and industrial interests. This approach is largely focused on the formation of the so-called social economy, the creation of new jobs in accordance with changing requirements for the competence of specialists.

In the scientific literature (Korchagina et al., 2016) was found that there are significant differences in the mechanisms of cluster development in European countries. It concerns the scale of cluster policy in different regions and differentiation of goals and methods of cluster policy. At the same time, it was emphasizing (Ketels, 2009) that there are two opposite approaches to understanding cluster policy: one of them considers agglomeration as a key factor (the agglomeration grows the competitiveness increase) and another one, on the contrary, considers competitiveness as the central element of cluster policy. 


\section{ENTREPRENEURSHIP AND SUSTAINABILITY ISSUES}

ISSN 2345-0282 (online) http://jssidoi.org/jesi/

2020 Volume 7 Number 4 (June)

http://doi.org/10.9770/jesi.2020.7.4(37)

It is important to note that the exact sciences use largely universal approaches of clustering but in the vast majority of cases they are outside of the scope of research in the field of economics. These methods could be successfully used as tools for evaluating the feasibility of implementing a cluster initiative. For instance, some authors (Polishchuk \& Kochergin, 2011) consider the issues of spatial data analysis based on multidimensional clustering using geoinformation systems, in particular an algorithm for using the maximum local distance method is used. It's based on principle to consistently combine objects into homogeneous groups (first is the closest) in a multidimensional feature space.

Some experts (Tolstova, 2011) used the analytic hierarchy process and cluster analysis and proposed to divide regions into clusters based on the criteria for assessing the investment climate at the level of the corresponding territorial units. It was found the function determined the value of the integral indicator of each region for the investment block.

The other experts (Moskovkin \& Arinella, 2017) propose to use matrix clustering: clusterization of countries of the world based on the Trade Competitiveness Map database; clusterization of enterprises that produce (or export) $m m$-types of similar products when each of them is characterized by indicators; clusterization of retail chains that sell $\mathrm{mm}$-types of similar products when each of them is characterized by $n n$-indicators etc.

Besides the coefficient method is widely used in the economic literature. For example, the method of location quotient calculating can be used to determine the integrated index of the clustering potential of a region.

Summarizing the conclusions of the experts in the field of clustering it could be said that the understanding of the essence of the cluster is changing in accordance with the current trends in the development of the economic model as a whole. In other words, the vision of clustering evolutionizes while preserving its generic features (Kolesnikov \& Khazalia, 2016). Unfortunately, a significant destructive factor of the clustering theory development is the high influence of the subjective component - most of the works are purely theoretical or, in contrast, they evaluate the cluster's performance based on achieving/not achieving the target values of ordinary economic indicators (Korableva et al., 2018). At the same time, the methodological component of the cluster approach stays largely out of the boundaries of such studies. A significant negative factor is the lack of strong links between using of clustering tools in the exact sciences (Pestunov et al., 2011) and in economics.

Nowadays many of the formed clusters are going through the collapse and crisis as well as the departure of the basic enterprises that formed the cluster core. This trend is caused not so much by intra-cluster processes but by a general change in the business environment and investment climate in the region. And no doubt it implies a considerable danger to innovation security (Gorochnaya, 2019).

The crucial issue of cluster is a process of defining the core since its viability directly depends on it (Trifonova, Borovskaya \& Epstein, 2018). In most cases the cluster core is determined either on the basis of the coefficient method (and its variants - by calculating the multipliers) or on the basis of a major industry player.

In the conditions of economic crisis, the cluster core is determined on the base of the coefficient method (Kostenko, 2017) and its varieties (Karayeva \& Shogenova, 2017) or the method of delegating control and management functions to the largest industry player (Battalova, 2012). They are generally applicable but do not have a sufficient flexibility and universality.

From the point of view of justifying the location of the cluster core it should be pay attention to calculation methods (Maltsev \& Davankov, 2017) that are largely used outside the scope of research in the field of economics. For example, the identification core algorithm for the high dimensional data clustering includes the following indicators: 
- the radius of the cluster core can be:

$$
R_{i}=\overline{r_{i}}+\sqrt{2} \sigma_{i}
$$

where $\overline{r_{l}}$ - average distance between the cluster center and its elements, $\sigma_{i}-$ mean-square deviation;

- $\quad$ the cluster density is determined by the formula:

$$
p_{i}=\frac{R_{i}}{\bar{N}_{\imath}}
$$

where $R i$ - the radius of the cluster core, $\bar{N}_{l}$ - the number of elements that make up the core.

The average density will be an estimate of the final clusterization result:

$$
\bar{p}=\frac{p_{1}+\cdots+p_{n c}}{p_{n c}}
$$

Of particular note, the mobile cluster core model should be mentioned: the authors of the paper have formulated the assumption that there is a mental, dynamic nature of the innovation cluster core which assumes the transition of the dominant company's function from production and business structures to large university and research centers.

It can be concluded that in the conditions of economic crisis both methods - determining the cluster core based on the coefficient method as well as the method of delegating control and management functions to the largest industry player - does not have a sufficient flexibility, objectivity and universality. In other words, there is a need to develop universal and - at the same time - accurate clustering methods with a minimum level of error which determine the correct position of the core not only base of the optimization of time and financial expenditure.

So, there is an objective need to improve both the theoretical basis of the cluster approach (taking into account the changes in the economics over the past twenty years) and the methodology by introduction of mathematical methods and models.

\section{Methods}

The methods are based on importance ranking of the main directions of business entities' work taking into account the following evaluation criteria: $R_{1}$ - recreation, $R_{2}$ - convenience, $R_{3}$ - products, $R_{4}-$ cognition, $R_{5}-$ service, $\mathrm{R}_{6}$ - comfort, $\mathrm{R}_{7}-$ safety. The following condition must be met:

$$
\sum_{i=1}^{6} \mathrm{R}_{\mathrm{i}}=1 .
$$

Within each of the selected directions $\mathbf{k}_{\mathbf{j}}$-organizations were ranked based on its number in their own direction. After that the main and secondary organizations were allocated while:

$$
\sum_{j=1}^{10} \mathrm{k}_{\mathrm{j}}=1 \text {. }
$$

Then each organization was evaluated in terms of the set of $\mathrm{R}_{\mathrm{i}}$-services provided by it. After that the arithmetical mean for an individual set of parameters $k_{j}\left(R_{i}\right)$ is defined for each organization. Similarly, values for the actual cluster center $\mathrm{Z}$ were found. To find the coordinates of the geometric center $\mathrm{M}$ of the cluster the average arithmetic value $\mathrm{k}_{\mathrm{j}}$ и $\mathrm{Z}$ was calculated for the respective axes. 


\section{ENTREPRENEURSHIP AND SUSTAINABILITY ISSUES}

ISSN 2345-0282 (online) http://jssidoi.org/jesi/

2020 Volume 7 Number 4 (June)

http://doi.org/10.9770/jesi.2020.7.4(37)

By defining the axes of coordinates in the system " $\mathrm{x}$ - the number of organizations (or the number of services)" and " $y$ - the arithmetical mean for an individual set of parameters (ranking)" a graph of the points density of the cluster was plotted.

It was suggested to mark out the thematic border and geographical border of the cluster. The thematic border includes the basic (cluster-forming) organizations. If even one of them goes out from the cluster the further work of the cluster will be impossible or poor. Geographical border includes others organizations and cluster can exist without them. But it will be "incomplete" in terms of the volume or security of provided services.

So, the expediency of an attract of each of the potential participants to the cluster as well as the possibility of exclusion of organizations that duplicate each other's functions can be assessed.

As part of the study, an analysis of domestic experience in the formation of the perimeter of the integration of corporate reporting information was carried out. System analysis, empirical research, principles of formal logic, synthesis and analysis of theoretical and practical material were used as research tools.

\section{Results}

There are several clustering methods that define the necessary data to determine the effectiveness of existing or creating cluster such as:

- K-means clustering method and hierarchical clustering when they try to find the partitioning of set of observations into a predefined number of clusters

- clustering of observations based on characteristics - it consists of searching for a subgroup among observations or searching for a subgroup among characteristics;

- clusterization method based on point density analysis where much attention is paid to the location of cluster objects in space and there is no need to select the size of the "union territory".

Currently, the methods for combining several cluster procedures, combining methods with data visualization and others are actively developing. It is important to use cluster algorithms that meet the invariance criteria in relation to the initial numbering (permutation) of clustered objects and invariance in relation to monotone transformations of similarity values.

There is also a clustering method based on point density analysis. When using this method much attention is paid to the location of cluster objects in space and there is no need to select the size of the association territory.

The methods and algorithms for clustering based on fuzzy equivalence relations are defined by studying the development and research of clustering methods and algorithms for data analysis systems. Besides both the clustering quality criteria (they are suitable for building an adaptive system) and adaptive clustering techniques are developed.

In most case this approach takes into consideration a stationary cluster that has clear limitations and scope. Therefore, not all clustering methods may be effective and appropriate for the "temporary" cluster that we are creating as part of a sport-dance competition.

The "temporary" cluster acts as a link that includes all the necessary activities of the structure and their complements. However, we need to define a clustering method that can be used to calculate more accurate data and make sure that it is appropriate to create a cluster at all. 
However, this approach takes into account the equivalence of all organizations including their economic might and the readiness of management to inter-cluster interaction without zero-sum game and other methods of daily operations that are no longer typical for individual organizations. This clustering system can be described by a linear function (Fig.1, position a).

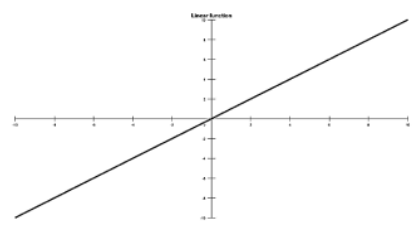

$\mathrm{a}$

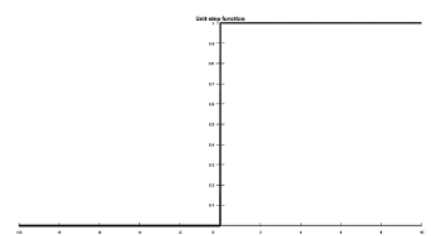

b

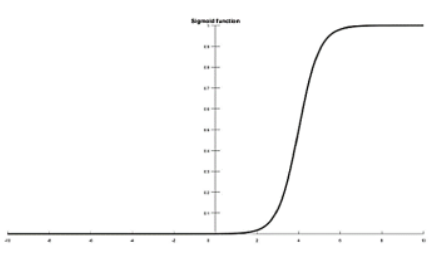

c

Fig. 1. Plot of functional relation Source: compiled by the authors

Threshold function (Fig.1, position b) allows to describe the "qualitative" jump that occurs when the "critical mass" of organizations wishing to enter into new economic relations within the cluster is exceeded. However, the "jump" will largely be determined by the number of organizations willing to participate in clusterization even if they are already ranked using weight coefficient.

The sigmoid function (Fig.1, position c) has the property of amplifying weak signals better than strong ones as well as preventing saturation from strong signals coming at the same time. Thus, it allows to evaluate their ability to cluster without "egalitarianism" but taking into account the capabilities of all incoming organizations. This process can be implemented by assigning the average weighted factor for each incoming organization taking into account all aspects - from economic soundness to management methods and assessing the need for its participation in the cluster.

The number of objects included in the cluster must meet the value of the criterion of optimality which determines the best possible functioning of the system. The correct selection of criteria plays a significant role in choosing the optimal solution. It is difficult to choose one of such criterions that would ensure the fullness of the requirements when describing an object. But the desire for a comprehensive solution and the assignment of a large number of criteria greatly complicates the task. Therefore, the number of criteria may differ for different tasks.

Let's assume that the following organizations are included in the "temporary" cluster that is being created for a single event in sport-dance competition (table 1). The table also shows the number of organizations that can potentially be involved in a particular area of cluster activity. Besides, it introduces the designations for each of the areas.

Now let's consider the relative similarity of the expected activities of organizations that are the part of the cluster based on plotting the density of points. Each object in the cluster has an individual set of parameters. The following criteria are offered: 1 - leisure; 2 - convenience; 3 - products; 4 - cognition; 5 - service; 6 - comfort; 7 - safety.

We will rank these criteria based on expert evaluation. For this case the sum of the seven criteria for an individual set of parameters will be equal to one. Each rank R will have its own special value. Next, we distribute the unit's fractions according to the criteria (Fig.2) and assign a letter denotation for each parameter: $R_{1}-$ leisure, $R_{2}-$ convenience, $\mathrm{R}_{3}$ - products, $\mathrm{R}_{4}$ - cognition, $\mathrm{R}_{5}$ - service, $\mathrm{R}_{6}$ - comfort, $\mathrm{R}_{7}$ - safety. 
Table 1. The potential organizations of the cluster

\begin{tabular}{|c|c|c|}
\hline Areas of work of organizations & $\begin{array}{c}\text { Number of } \\
\text { organizations }\end{array}$ & Letter denotation \\
\hline Food services & 3 & $\mathrm{k} 1$ \\
\hline Equipment and accessories for dancing & 6 & $\mathrm{k} 3$ \\
\hline Transport organization & 2 & $\mathrm{k} 4$ \\
\hline Beauty industry (makeup and hairstyles) & 4 & $\mathrm{k} 5$ \\
\hline Hotels (accommodation for participants of the competition) & 2 & $\mathrm{k} 6$ \\
\hline Model agency (organization shows dresses) & 1 & $\mathrm{k} 7$ \\
\hline Museum-exhibitions of the dance history & 1 & $\mathrm{k} 8$ \\
\hline Tourist organization (excursions to the event) & 1 & $\mathrm{k} 9$ \\
\hline Security and control of order during the competition & & 2 \\
\hline
\end{tabular}

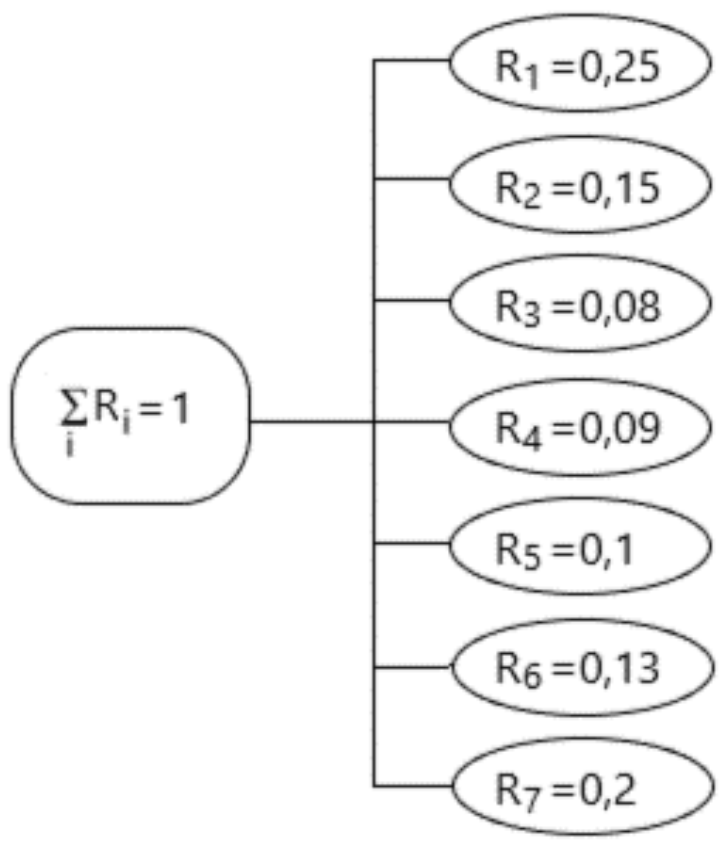

Fig. 2. Ranking criteria for individual parameters by significance Source: compiled by the authors 
Then we will distribute the received data in according to the description of each directions: $k_{1}(y)=\left\{R_{1}, R_{2}, R_{3}, R_{5}\right\}$; $\mathrm{k}_{2}(\mathrm{y})=\left\{\mathrm{R}_{2}, \mathrm{R}_{3}, \mathrm{R}_{5}\right\} ; \quad \mathrm{k}_{3}(\mathrm{y})=\left\{\mathrm{R}_{2}, \mathrm{R}_{5}, \mathrm{R}_{6}\right\} ; \quad \mathrm{k}_{4}(\mathrm{y})=\left\{\mathrm{R}_{2}, \mathrm{R}_{3}, \mathrm{R}_{5}\right\} ; \quad \mathrm{k}_{5}(\mathrm{y})=\left\{\mathrm{R}_{1}, \mathrm{R}_{2}, \mathrm{R}_{5}, \mathrm{R}_{6}\right\} ; \quad \mathrm{k}_{6}(\mathrm{y})=\left\{\mathrm{R}_{1}, \mathrm{R}_{2}, \mathrm{R}_{5}, \mathrm{R}_{6}\right\}$ $\mathrm{k}_{7}(\mathrm{y})=\left\{\mathrm{R}_{1}, \mathrm{R}_{4}\right\} ; \mathrm{k}_{8}(\mathrm{y})=\left\{\mathrm{R}_{1}, \mathrm{R}_{3}, \mathrm{R}_{4}, \mathrm{R}_{5}\right\} ; \mathrm{k}_{9}(\mathrm{y})=\left\{\mathrm{R}_{5}, \mathrm{R}_{6}, \mathrm{R}_{7}\right\} ; \mathrm{k}_{10}(\mathrm{y})=\left\{\mathrm{R}_{1}, \mathrm{R}_{3}, \mathrm{R}_{4}, \mathrm{R}_{5}\right\}$.

Substituting numeric values for the criteria significance levels we get: $\mathrm{k}_{1}(\mathrm{y})=\{0,25 ; 0,15 ; 0,08 ; 0,1\}$; $\mathrm{k}_{2}(\mathrm{y})=\{0,15 ; 0,08 ; 0,1\} ; \quad \mathrm{k}_{3}(\mathrm{y})=\{0,15 ; 0,1 ; 0,13\} ; \quad \mathrm{k}_{4}(\mathrm{y})=\{0,15 ; 0,08 ; 0,1\} ; \quad \mathrm{k}_{5}(\mathrm{y})=\{0,25 ; 0,15 ; 0,1 ; 0,13\}$ $\mathrm{k}_{6}(\mathrm{y})=\{0,25 ; 0,15 ; 0,1 ; 0,13\} ; \quad \mathrm{k}_{7}(\mathrm{y})=\{0,25 ; 0,09\} ; \quad \mathrm{k}_{8}(\mathrm{y})=\{0,25 ; 0,08 ; 0,09 ; 0,1\} ; \quad \mathrm{k}_{9}(\mathrm{y})=\{0,1 ; 0,13 ; 0,2\}$; $\mathrm{k}_{10}(\mathrm{y})=\{0,25 ; 0,08 ; 0,09 ; 0,1\}$.

From the data obtained above, we find the coordinates of the points on the Y-axis (the arithmetical mean of data for an individual set of parameters):

$\mathrm{k}_{1}(\mathrm{y})=(0,25+0,15+0,08+0,1) / 4=0,145$;

$\mathrm{k}_{2}(\mathrm{y})=(0,15+0,08+0,1) / 3=0,11$;

$\mathrm{k}_{3}(\mathrm{y})=(0,15+0,1+0,13) / 3=0,126$;

$\mathrm{k}_{4}(\mathrm{y})=(0,15+0,08+0,1) / 3=0,11$;

$\mathrm{k}_{5}(\mathrm{y})=(0,25+0,15+0,1+0,13) / 4=0,157$;

$\mathrm{k}_{6}(\mathrm{y})=(0,25+0,15+0,1+0,13) / 4=0,157$;

$\mathrm{k}_{7}(\mathrm{y})=(0,25+0,09) / 2=0,17$

$\mathrm{k}_{8}(\mathrm{y})=(0,25+0,08+0,09+0,1) / 4=0,13$;

$\mathrm{k}_{9}(\mathrm{y})=(0,1+0,13+0,2) / 3=0,143$;

$\mathrm{k}_{10}(\mathrm{y})=(0,25+0,08+0,09+0,1) / 4=0,13$.

Accordingly, we get the coordinates of ten points of corporate business line on the X-axis (the number of organizations of this corporate business line) and on the Y-axis (the arithmetical mean of an individual set of criteria): $\mathrm{k} 1=\{3 ; 0,145\} ; \mathrm{k} 2=\{6 ; 0,11\} ; \mathrm{k} 3=\{2 ; 0,126\} ; \mathrm{k} 4=\{4 ; 0,11\} ; \mathrm{k} 5=\{2 ; 0,157\} ; \mathrm{k} 6=\{1 ; 0,157\} ; \mathrm{k} 7=\{1 ; 0,17\}$; $\mathrm{k} 8=\{1 ; 0,13\} ; \mathrm{k} 9=\{2 ; 0,143\} ; \mathrm{k} 10=\{1 ; 0,13\}$.

Due to the fact that some activities of the included economic units imply the presence of several organizations $\left(\mathrm{k}_{1}\right.$, $\mathrm{k}_{2}, \mathrm{k}_{3}, \mathrm{k}_{4}, \mathrm{k}_{5}, \mathrm{k}_{9}$ ) it is necessary to further divide the already separated unit's fractions between these organizations.

Ranking by significance indicates that dance and sports events will not be complete without a Gala-concert and master-classes for participants of the competition. At the same time "secondary" organizations include a company that organizes a museum of the dance history; a company that organizes the show of costumes for dancing; a second hotel complex; two organizations that provide food services and a one tourist organization. The "third plan" includes one organization that provides food services; six stores with inventory and equipment for dancing as well as all the masters or organizations that provide makeup and hair services.

Let's explain the abovementioned: three organizations that provide food during the competition are evaluated in accordance with certain parameters that meet the conditions of the event (menu, readiness to move, staff, service rate, decoration of dining area) as follows: $1^{\text {st }}$ has a rank of 0,$05 ; 2^{\text {nd }}-0,04 ; 3^{\text {rd }}-0,03$. At the same time, it should be emphasized that the sum of the ranks of all three organizations is equal to the rank of this direction.

The stores that sell inventory, equipment and accessories for dancing represents by six organizations. In this case the significance is distributed in accordance with the diversity of the assortment in relation to the conducted disciplines: 1 st $-0,010 ; 2$ nd $-0,016 ; 3$ rd $-0,015 ; 4$ th $-0,018 ; 5$ th $-0,013 ; 6$ th $-0,018$. 
Two transport organizations must be as mobile as possible and have high speed and quality of passenger transportation: 1 st $-0,05 ; 2$ nd $-0,05$. Two selected organizations have an equal fraction since they not only provide the same service but also meet the necessary requirements equally.

The beauty industry must be represented by four organizations or private masters. Due to the fact that the sportdancing competition is a large-scale event it would be more acceptable to cooperate with organizations since there are several specialists work instead of one. The choice of a specialist (master) is based on the client's preferences, so it is impossible to clearly identify more or less significant organizations. Thus, the ranking for this organizations is equal to 0,015 for each.

To provide accommodation services we selected two hotel complexes often involved in such events. They are located in different territories of the Russian Federation. The distribution of significance in this case was taking into account the scale of the hotel complex network: $1^{\text {st }}-0,09 ; 2^{\text {nd }}-0,06$.

Two organizations were invited to safeguard the event. It is unlikely that two security organizations can work effectively together within the framework of a single event since each firm operates on its own principle and according to a special developed system. Therefore, the distribution of significance corresponds to the number of provided services and readiness to participate in a sports event of a cluster type: $1^{\text {st }}-0,08 ; 2^{\text {nd }}-0,12$.

Thus, the ranking of the significance of organizations included in the cluster can be represented as a graph (Fig.3).

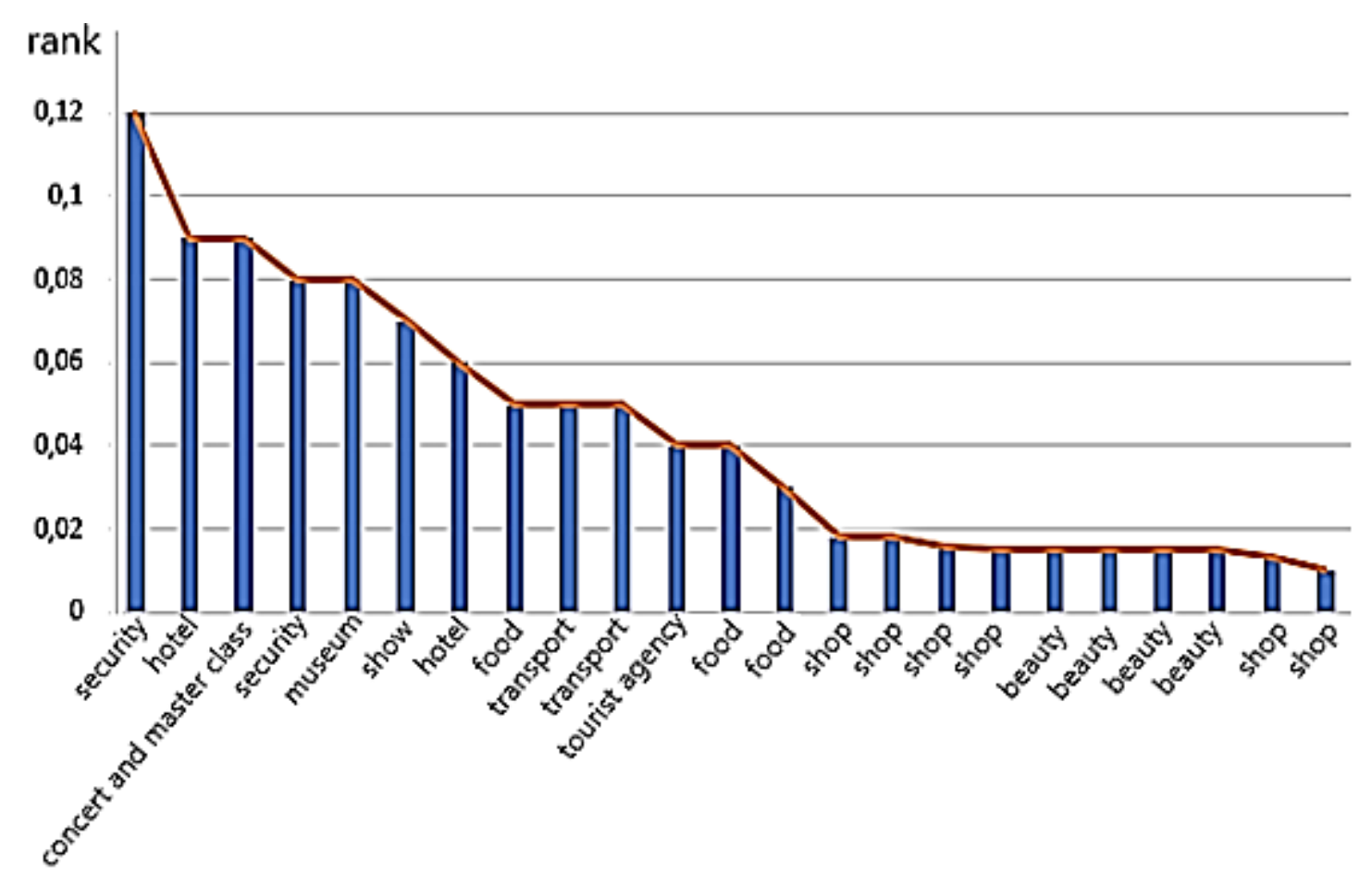

Fig. 3. Significance of organizations in descending order Source: compiled by the authors

We use the indicated approach to grouping for a newly created "temporary" sport-dance cluster taking into account the fact that the actual center $\mathrm{Z}$ of the created cluster is a dance organization with the coordinates "ranking" $\{0,08 ; 0,09 ; 0,1 ; 0,13\}=0,1$ and "the number of objects/services/directions" is equal to 3 . In this coordinate system we will draw the actual center $\mathrm{Z}$ and the geometric center $\mathrm{M}$ (its coordinates are calculated as 
the arithmetical mean values of $\mathrm{k}_{\mathrm{i}}$ and $\mathrm{Z}$ on the corresponding axes) and we will also highlight the geographical and thematic borders (Fig.4).

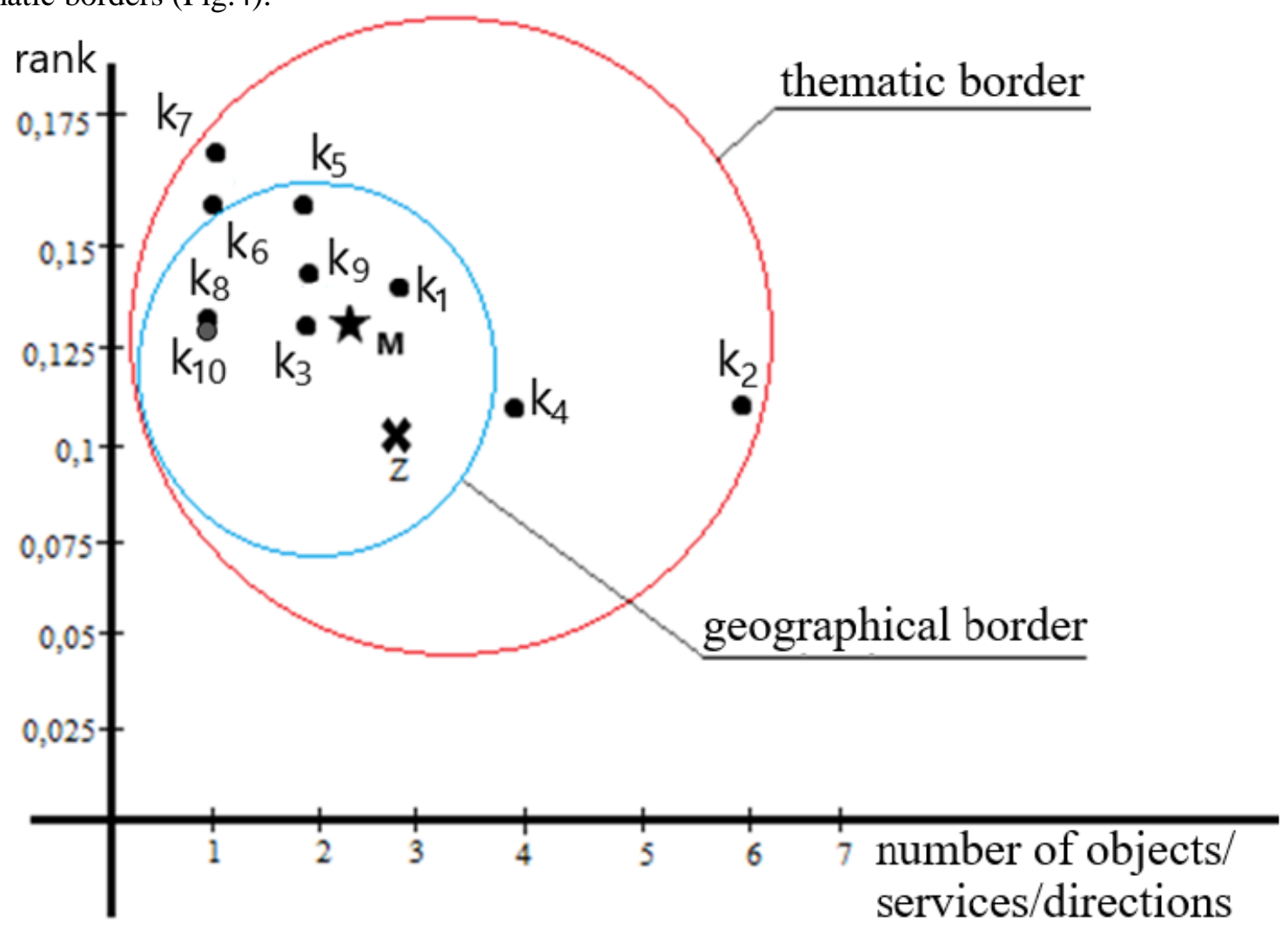

Fig. 4. Point density in a sport-dance cluster Source: compiled by the authors

In the sport-dance cluster the main focus is made on the need to move the event objects because of sport-dance competitions are often held in completely different locations. Thus, the thematic border goes to the background and the basis for such cluster is food facilities, hotel complexes, security and transport organizations.

\section{Implementations and Conclusion}

On the basis of this research it is possible to come to the following conclusions ${ }^{\wedge}$

1. When the actual center coincides with geometric center it indicates that the actual center does not have a significant "attractive force" and it perceives as an equal partner but not the center of grouping.

2. The relative position of the geometric center and the actual center will be determined by the resources available to the actual center and their diversity - the more resources the far away these centers will be from each other.

3. The narrower the cluster boundaries the greater the concentration of resources at the actual center and the less need for clusterization (most likely it will be changed by subcontracting/outsourcing).

4. Clusters based on a thematic border will be characterized by a stationary association. If the basis of the association is a geographical border then such cluster is considered mobile and ready to function on different territories.

5. The opportunity for adjusting the location map of cluster members (formatting the cultural and thematic landscape) are indicated. It is very interesting for developing programs for creating flexible models of innovation 


\section{ENTREPRENEURSHIP AND SUSTAINABILITY ISSUES}

ISSN 2345-0282 (online) http://jssidoi.org/jesi/

2020 Volume 7 Number 4 (June)

http://doi.org/10.9770/jesi.2020.7.4(37)

clusters with a significant number of mobile objects and experimental sites. On the other hand, it can be successfully used for short-term cluster initiatives such as organizing competitions in dance, sports, eSports events etc.

\section{References}

Abdurakhmanov A.V. (2018). Expert model of regional and industrial cluster. Bulletin of MSEI, №4, pp. 5-9.

Battalova A. A. (2012). Vertically integrated oil company - the core of the cluster. Electronic scientific journal "Oil and gas business", 2 , 368-380.

Bondarenko N. E. (2016). Cluster theory of economic development: the history of formation and formation. International scientific journal "Symbol of science", 2-2(14), 116-121.

Charykova O. G., \& Markova E. S. (2019). Regional clusterization in the digital economy. Regional economy, 15(2), 409-419.

Gorochnaya V. V. (2019). Cluster formation and innovative security in the regions of the Western Borderlands of Russia: inventory and main trends of development. Regional economy and management: electronic scientific journal. ISSN 1999-2645. 3(59) https://eee$\underline{\text { region.ru/article/5911 }}$

Egorova L. A. (2014). Clusterization of the economy as a promising direction of its development. Concept. Special issue № 05. ART 14545. URL: http://e-koncept.ru/2014/14545.htm

El Idrissi, N. E. A., Ilham Zerrouk, I., Zirari, N., Monni, S. 2020. Comparative study between two innovative clusters in Morocco and Italy. Insights into Regional Development, 2(1), 400-417. http://doi.org/10.9770/IRD.2020.2.1(1)

Karayeva F. E., \& Shogenova Z. H. (2017). The choice of enterprises for forming the core of a regional cluster in the conditions of fuzzy information. St. Petersburg economic journal, 1, 91-105.

Ketels, Ch. (2009). Clusters, Cluster Policy, and Swedish Competitiveness in the Global Economy. Harvard Business School and Stockholm School of Economics. Expert report no. 30 to Sweden's Globalisation Council, p. 66.

Kiseleva A. M., \& Smolinski K. A. (2018). Cluster projects in the public-private partnership as a tool for the development of the digital economy. Bulletin of the faculty of management of St. Petersburg state economic University. Scientific journal, Issue 3 (P.1), pp. 53-58.

Korableva, O. N., Kalimullina, O. V., \& Mityakova, V. N. (2018). Innovation activity data processing and aggregation based on ontological modelling. Paper presented at the 2018 4th International Conference on Information Management, ICIM 2018, 1-4. http://doi.org/10.1109/INFOMAN.2018.8392659

Kolesnikov A. M., \& Khazalia N. A. (2016). The analysis of the notion of "cluster". Approaches to classification. Scientific journal of NIU ITMO. Series "Economics and environmental management", 4, 19-25.

Korchagina I. V., Buvaltseva V. I., \& Korchagin R. L. (2016). Foreign experience of forming clusters of small enterprises in the regions: approaches and mechanisms. Economics and modern management: theory and practice. Collection of articles based on the materials of the LXVII international scientific and practical conference, 11(62), 90-99.

Kostenko O. (2017). Identification of agro-industrial clusters using localization coefficients. Problems of management theory and practice, $5,88-93$.

Maltsev Yu. G., \& Davankov A. Yu. (2017). Method of cluster core recognition. Izvestiya of higher educational institutions. Ural region, 2, 33-38.

Moskovkin V. M., \& Arinella K. (2017). Matrix clusterization as clusterization of matrices of the same dimension. Scientific Bulletin of the Belgorod state University. Series: Economics. informatics, 23(272), 123-127.

Nikulina O. V., \& Yakunina Yu. K. (2011). Model of innovative development based on optimization of clusterization methods of regional economy. Regional Economy: Theory and Practice, 42, $42-49$. 


\section{ENTREPRENEURSHIP AND SUSTAINABILITY ISSUES}

ISSN 2345-0282 (online) http://jssidoi.org/jesi/

2020 Volume 7 Number 4 (June)

http://doi.org/10.9770/jesi.2020.7.4(37)

Nielsen, Kaspar, \& Nielsen, Merete D. (2019). Clusters in the Circular Economy Building Partnerships for Sustainable Transition of SMEs. Printed on sustainable paper according to the principles of The Nordic Swan Ecolabel promoting circular economy. TCI Network, pp. 124.

Pestunov I. A., Berikov V. B., Kulikova E. A., \& Rylov S. A. (2011). Ensemble clustering algorithm for large data arrays. Autometry, 3(47), 49-58.

Petrenko, Y., Vechkinzova, E., \& Antonov, V. (2019). Transition from the industrial clusters to the smart specialization of the regions in Kazakhstan. Insights into Regional Development, 1(2), 118-128. https://doi.org/10.9770/ird.2019.1.2(3)

Polishchuk, Yu. M., \& Kochergin, G. A. (2011). Use of geoinformation systems for complex analysis of spatial data based on multidimensional clustering. Geoinformatics, 2, 11-15

Tolstova, M. L. (2011). Assessment of the investment potential of the Volga Federal district regions based on the clusterization method. Actual Problems of Economics and Law, 4, 218-221.

Trifonova, N. V., Borovskaya, I. L., Epstein, M. Z. (2018). Analysis of dynamic changes in the stable component (core) of innovation clusters. Engineering education, 23, 152-158.

Turgel, I.D., Bozhko, L.G., \& Zinovyeva, E.G. (2019). Cluster approach to organization of special economic zones in Russia and Kazakhstan. R-ECONOMY, 5(2), 71-78.

\section{Arkadii SIMDIANKIN}

Doctor of technical Sciences, Professor, Professor of the «Economics and law» department, Russian state university of physical education, sport, youth and tourism (SCOLIPE). Research interests: clustering; economic security; mathematical methods in Economics.

ORCID ID: https://orcid.org/0000-0001-9761-6183

\section{Pavel PROBIN}

Candidate of economic Sciences, associate Professor, associate Professor of the «Economics and law» department, Russian state university of physical education, sport, youth and tourism (SCOLIPE). Research interests: financial markets; taxation; investment; marketing.

ORCID ID: https://orcid.org/0000-0003-3027-7214

\section{Larisa GERASIMOVA}

Doctor of Economic Sciences, Professor, Department of Economics and Management in Construction, Moscow State University of Civil Engineering (National Research University) (MGSU). Research interests - accounting, integrated reporting, management accounting, financial control, corporate finance.

ORCID ID: https://orcid.org/0000-0003-1144-6019

\section{Zhanna KEVORKOVA}

Doctor of Economics, Professor, Professor of the Accounting, Analysis and Audit Department of the Financial University under the Government of the Russian Federation. Research interests - accounting, financial control, control and audit in the field of procurement, forensic.

ORCID ID: https://orcid.org/0000-0002-8674-4216 


\section{ENTREPRENEURSHIP AND SUSTAINABILITY ISSUES}

ISSN 2345-0282 (online) http://jssidoi.org/jesi/

2020 Volume 7 Number 4 (June)

http://doi.org/10.9770/jesi.2020.7.4(37)

\section{Vadim DIKIKH}

$\mathrm{PhD}$ in Economics, State and municipal administration and law, Moscow City Teacher Training University. Research interests - Investment management, property valuation, economics of organizations

ORCID ID: https://orcid.org/0000-0001-5430-4868

\section{Aslan NURMANOV}

Candidate of economic Sciences, senior lecturer of the Department "Public administration, Finance and marketing" Aktobe regional state University named after K. Zhubanov

ORCID ID: https://orcid.org/0000-0001-9601-771X 